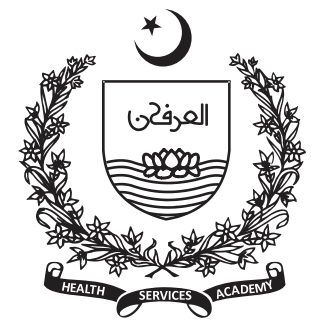

\title{
Cardiovascular Disease Risk Factors' Awareness and Prevalence among College Students in Karachi City
}

\author{
Uzma Aamir Jilani ${ }^{1}$, Mehveen Iqbal2 ${ }^{2}$, Syed Aamir Jilani ${ }^{3}$
}

1Postgraduate student (Biomedicine by Research), Management and Science University, Malaysia

2Pathology

United Medical and Dental

College, Karachi Pakistan

${ }^{3}$ General Physician

Private Practice, Karachi

Pakistan

Corresponding Author:

Uzma Aamir Jilani

Email: jilanies@yahoo.com

\begin{abstract}
Background: The aim of the study was to determine the health beliefs and prevalence of cardiovascular disease (CVD) risk factors among the college students of Karachi city.
\end{abstract}

Methods: A survey among students of the United Medical and Dental College and non-medical students was performed from the period of October 2019 to January 2020. A validated questionnaire was used to identify the health beliefs of the subjects, related to CVD and its determinants, along with a brief medical history to determine the prevalence of risk factors. The data was analysed by using SPSS version 23.

Results: Among total subjects of 140, 53 (37.8\%) males and $87(62.1 \%)$ females participated in the study. The analysis presented an adequate knowledge of CVD and its determinants among 133 (95\%) of the respondents. $112(80 \%)$ of the participants demonstrated a significantly positive attitude and supported the primary prevention of CVD. However, the practices were found optimum in $80(60 \%)$ of the respondents only, the rest were not up to the mark. It was identified that $69 \%$ of the respondents had at least one of the risk factors leading to CVD, which is a significant proportion.

Conclusion: The majority of the participants of this study were aware of the CVD and its determinants, however, the practices observed for the primary prevention of CVDs were not up to the standard. Risk factors were significantly pervasive among the participants. The findings of this survey support the need for modification of lifestyle to promote primary prevention of CVD from an early age.

Keywords: Cardiovascular disease, mortality, risk factors, awareness and practices

\section{Introduction}

7 he global issue of cardicrascular discase (CVD) mortality and morbidity is continuously on the rise and affecting developing countries more than the developed ones due to lack of resources, poor healthcare facilities, pollution, low education, and socioeconomic stress besides the other specific CVD risk factors (1). To talk about Pakistan, primary prevention programs are not formulated in most of the places and where exist, not implemented vividly by the authorities. Non compliance by the public is another hindrance. The poor socio-economic profile and low literacy among them restrict access and compliance with awareness and prevention programs (2). CVD is the leading cause of death in Pakistan (3). Sudden cardiac death, stroke and other complications of CVDs are the major causes of disability and increased mortality in Pakistan as those living in slums and rural areas do not have access to 
primary healthcare or cannot afford timely treatment to control the disease at an early stage (2).

With the growing economic situation around the globe, the best strategy is primary prevention, through awareness and screening programs $(4,5)$. Many of the risk factors leading to CVDs are modifiable such as smoking, hypertension, diabetes, and a sedentary lifestyle (6). All these hazards are significantly prevalent in Pakistan (7). An alarming trend has been found over the last decade, which is an incidence of CVD at an earlier age around 40s (8). Consumption of junk food, high in 'bad' fats, sodas, energy drinks, smoking, drug abuse, increased screen-time and physical inactivity among the country's younger generation are some of the determinants of a shift of CVD incidence towards an early age (8).

The association of CVD with risk factors is well established. Some of these determinants are uncontrollable such as age, gender, ethnicity, and family history. While age and CVD association is more marked in males, females have found to be more vulnerable to adverse CVD outcomes due to many other factors such as hormonal fluctuations, pregnancy-related issues, and non-compliant attitude $(7,9)$. Besides these many other elements impose a serious threat to cardiovascular function such as smoking, hypertension, obesity, diabetes, hypercholesterolemia, socioeconomic stress, and sedentary lifestyle $(7,10)$. Clustering of these risk factors is also common and exerts an added risk (11).

The main objective of this survey was to assess the younger generation's health beliefs regarding CVD and risk factors involved and to determine the presence of risk factors among them. Awareness campaigns may help in reducing the population's exposure to controllable hazards, early diagnosis of disease and hence contribute to primary and secondary prevention strategies $(12,13)$.

\section{Methodology}

This cross-sectional survey was conducted from October 2019 to January 2020, in Karachi. The target population was undergraduate and postgraduate students 18 to 40 . The researchers managed to get 140 respondents of those 70 were medical students of the United Medical and Dental College (UMDC). Ethical approval had been obtained from the research committee of the UMDC. The students approached randomly and requested to fill out a questionnaire for knowledge attitude and practices (KAP) regarding
CVD risk factors. The rest of the respondents were non-medical students approached through a google survey form by using the snowball technique. The questionnaire adopted was designed, validated, and used previously by a researcher, and permission was taken before the study (14). The questionnaire was in English language and comprised of five parts including, Demography, questions on Knowledge, Attitude, and Practices regarding CVD risk factors, and a brief medical history. There were two parts for knowledge, in the first part the subjects were asked to identify the risk factors of CVD, whereas the second part comprised of some statements related to CVD and the respondents were given the choices of true, false, and 'do not know'. Each correct answer for knowledge part 1 marked 2 points, whereas in the second part the responses are coded as correct $=3$, incorrect=2, do not know=1, and the total score for knowledge was calculated. There were 13 items to assess the attitude towards CVD and its risk factors and the responses were marked by a Likert scale of 1 to 5 . The positive attitudes which were 11 in number, were marked as Strongly Agree $=5$, Agree $=4,3$ Neutral=3, Disagree $=2$, and Strongly disagree $=1$. The negative attitudes were marked in reverse order. The practices were assessed by 11 items, on a Likert scale of 1-4, where 4 represented 'always', 3 'frequently', 2 'seldom', and 1 ' never' for all positive items, whereas the last 5 negative practices were marked in reverse order. A few questions about the participant's medical history were asked in the end. The statistical inferences were drawn by transferring the data on the Statistical Package for Social Sciences version 23, whereas $\mathrm{P}<0.05$ was considered significant. Frequencies with mean and standard deviation were described for all variables.

\section{Results}

Among the total survey population $(\mathrm{n}=140), 70(50 \%)$ were medical students and the rest were from nonmedical fields. More than half, $87(62 \%)$ of the subjects were female and $108(77 \%)$ of the subjects including male and females were below 25 .

The mean and standard deviation values for knowledge, from this study, were 60.38 and 7.38 respectively from the total obtainable score of 75 . The minimum and maximum scores for knowledge were 33 and 71 , respectively. Seventy-eight $(56 \%)$ of the respondents answered most of the knowledge 
questions correctly and achieved scores of 60 and above. Whereas 55 (39\%) of the respondents scored between 46 to 60 . Only seven people gained very poor knowledge scores. There was a negligible difference in knowledge score between medical and non-medical students.

Figures 1 and 2 show the number of correct and incorrect responses to questions regarding CVD and its risk factors. More than $60 \%$ of the subjects could recognize the clinical conditions that may or may not cause CVD, except for Diabetes Mellitus which was answered correctly by only $50 \%$. Heart attack and stroke are included in CVDs and answered incorrectly by the majority of the respondents. Out of 140 study subjects, more than $120(85.7 \%)$ subjects had a good level of knowledge about the association of gender and age with heart disease, $105(75 \%)$ were able to correctly identify the association of smoking with heart disease, more than 100 (71\%) were aware of obesity and physical activity association with CVD. Almost all the subjects answered correctly to conditions that do not impose a risk for CVD.

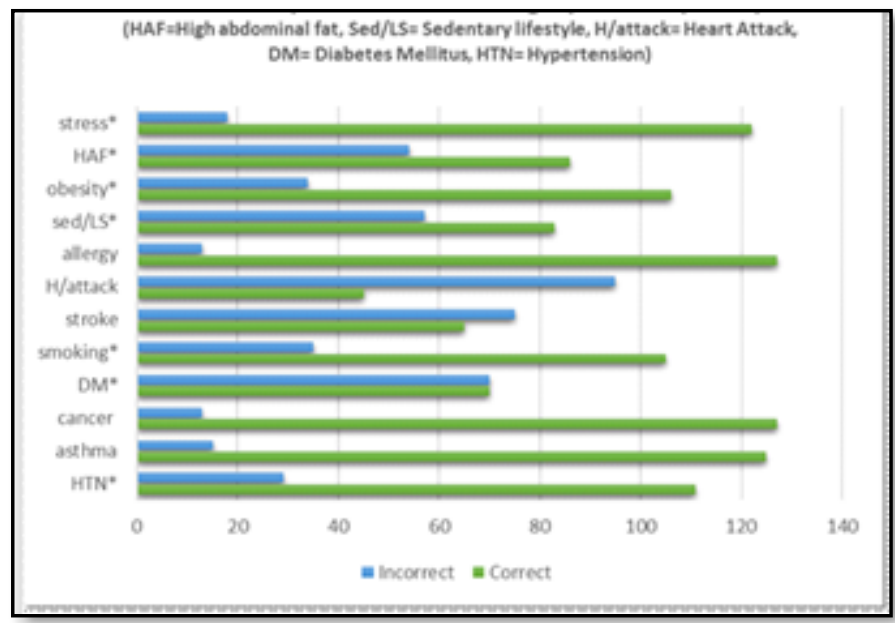

Figure 1: Frequencies for knowledge questions (part 1)

The mean score obtained for the attitude part was 57.65 and the standard deviation was 4.81 , with the minimum and maximum scores as 42 and 65, respectively. It had been identified that the subjects had a positive attitude towards CVD prevention, as $112(80 \%)$ of the respondents scored above 55. Most of the subjects agreed strongly to physical activity and a healthy diet. A negligible difference was found

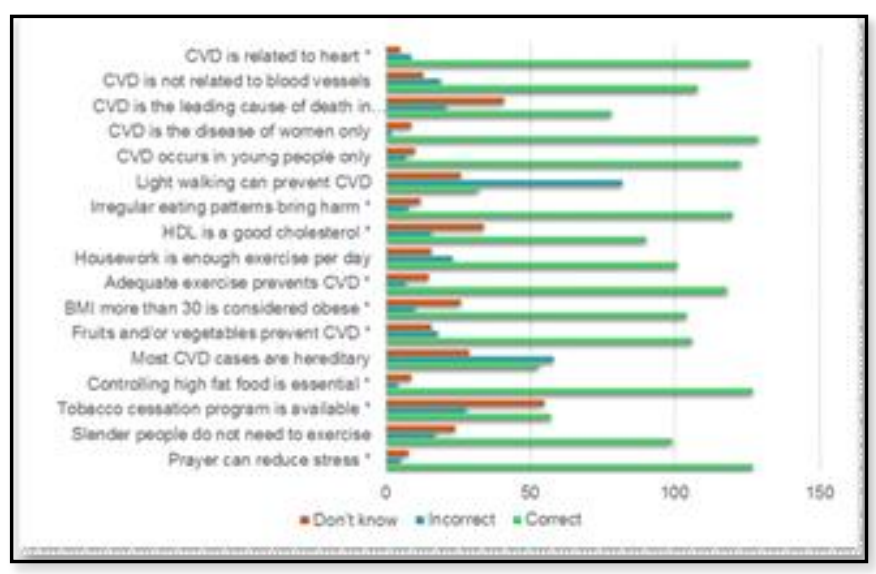

Figure 2: Frequencies for knowledge questions related to CVD

between attitude scores for medical and non-medical students. The frequencies for attitude towards CVD prevention are shown in Figure 3.

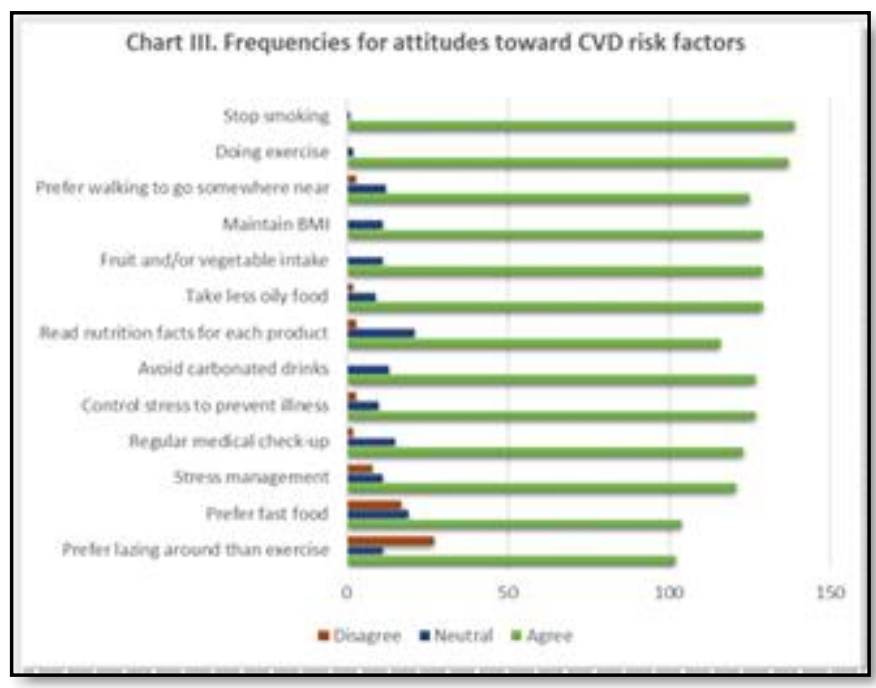

Figure 3: Frequencies for attitude toward CVD risk factors

The mean practice score obtained was 34.22 and standard deviation of 5.74, with the minimum and maximum scores as 17 and 44, respectively. Among 140 subjects, $87(62 \%)$ of the respondents scored between 34 and 44, which indicated that overall the lifestyle and dietary habits were optimum. A negligible difference was found for practices between medical and non-medical students. The frequencies for practices regarding CVD prevention are shown in Figure 4. 


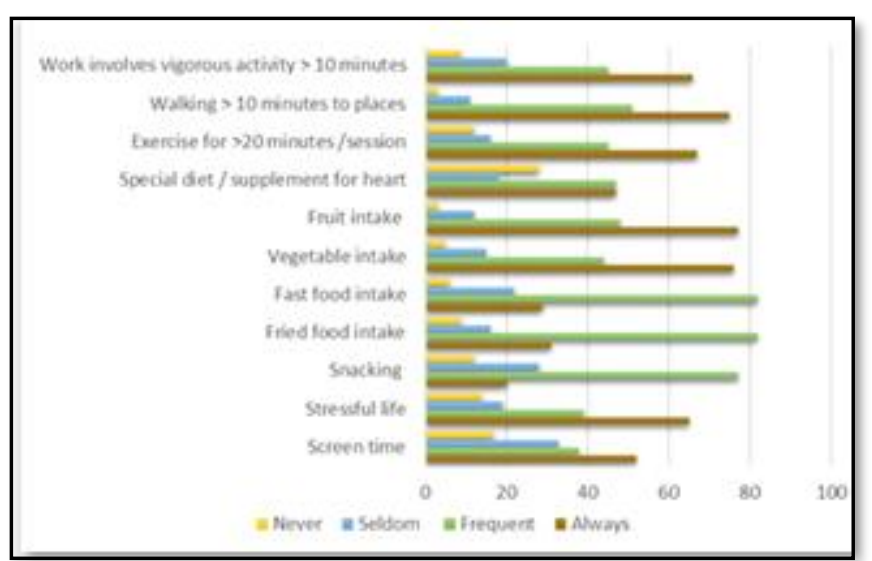

Figure 4: Frequencies of practices responses to each statement $(n=140)$

Results for the association of genders with knowledge, attitude, and practice toward the prevention of CVD are summarized in table 1 . After testing with an independent sample $t$-test, $P$-value obtained for knowledge was .002, which indicate that there is a significant difference in knowledge scores regarding risk factors of CVD between different genders. Females scored better than male subjects. On the other hand, the p-values for attitude and practices were more than 0.05 , indicating no significant difference for these variables among gender groups.

Table I: Frequencies of Knowledge, Attitude and Practices, and Gender Difference of Knowledge, Attitude, Practices score

\begin{tabular}{|l|l|l|l|l|l|}
\hline Variable & Gender & $\begin{array}{l}\boldsymbol{n} \\
\mathbf{( \% )}\end{array}$ & Mean (SD) & $\begin{array}{l}\boldsymbol{t} \text { - } \\
\text { statistics } \\
(\mathbf{d f})\end{array}$ & $\begin{array}{l}\boldsymbol{P} \text { - } \\
\text { Value }\end{array}$ \\
\hline Knowledge & Male & 53 & $57.91(8.603)$ & $\begin{array}{l}-3.204 \\
(138)\end{array}$ & .002 \\
\hline & Female & 87 & $61.90(6.104)$ & & \\
\hline Attitude & Male & 53 & $\begin{array}{l}57.26 \\
(4.919)\end{array}$ & $\begin{array}{l}-0.753 \\
(138)\end{array}$ & .453 \\
\hline & Female & 87 & $\begin{array}{l}57.90 \\
(4.757)\end{array}$ & & \\
\hline Practices & Male & 53 & $\begin{array}{l}33.89 \\
(5.976)\end{array}$ & $\begin{array}{l}-0.548 \\
(138)\end{array}$ & .584 \\
\hline & Female & 87 & $\begin{array}{l}34.44 \\
(5.621)\end{array}$ & & \\
\hline
\end{tabular}

In the last part of the questionnaire, a brief medical history was asked, and it was identified that $58 \%$ of respondents had a family history of diabetes, whereas $6 \%$ were known cases of diabetes. Family history of dyslipidemia and CVD was present in more than 35\% of the subjects. The prevalence of some other risk factors is shown in Figure 5. This indicates that more than $69 \%$ of the respondents had at least one of the CVD risk factors, which is a significant finding.

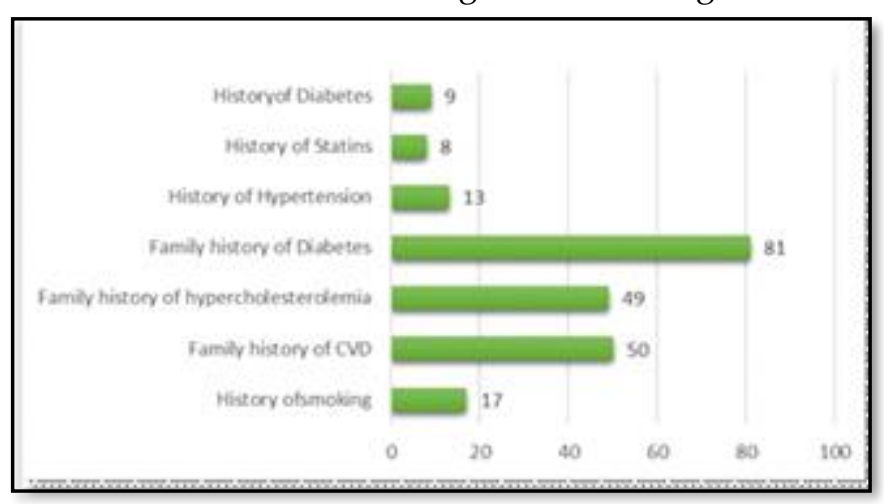

Figure 5: CVD risk factors among participants $(n=140)$

\section{Discussion}

In the current study two variables were being assessed to relate with KAP, which were gender, and field of study (medical and non-medical). However, most of them showed no significant difference in health beliefs regarding the risk of CVD, except that the females had more knowledge than males. Similar findings have been reported by other researchers (14). The current study demonstrated satisfactory outcomes in terms of CVD knowledge and attitude. Fifty-six per cent (56\%) of the respondents had knowledge scores above the mean score, and demonstrated adequate knowledge, whereas 39\% answered more than half of the questions correctly, only $4 \%$ depict poor knowledge. This is contradictory to research studies conducted among the Karachi population in 2015, where the knowledge level was found to be inadequate (15). Although the prevalence of CVD is significantly high worldwide, the awareness level is reported to be inadequate among the general public, especially in low, and middle-income countries (16). Findings of a qualitative study among urban slums in Nairobi demonstrated that there was poor knowledge about CVD and risk factors involved (12). Gaps in knowledge of CVD and the risk factors were strongly associated with the low levels of literacy in the Sub Saharan region and found to be important barriers in effective prevention and treatment (17). A research performed in the U.S identified that awareness level was lower in women with lower education and income, and among ethnic minorities (18). In the current study, a misconception was found that light 
walking prevents CVD and only $25 \%$ of the respondents answered this question correctly. Lack of knowledge was found in many respondents $(60 \%$ to $65 \%)$ regarding the hereditary association of CVD and the existence of an anti-tobacco program in Pakistan. Regarding risk factors knowledge, more than $75 \%$ of the respondents identified stress, obesity, smoking, and hypertension correctly whereas only $50 \%$ recognized diabetes as a CVD risk factor.

For the health beliefs, $81 \%$ demonstrated a positive attitude regarding CVD and the risk factors involved. Nearly all of the subjects agreed to stop smoking and working out physically. A healthy diet, stress management, and regular health checks were also agreed upon by most of them. On the other hand, more than half of the subjects preferred fast food and lazing around, which is alarming but most expected as more than $60 \%$ of the subjects belonged to the younger age group (18-25). Fast food indulgence and reduced physical activity due to increased screen-time are the main trends found in the youth nowadays $(19,20)$. Fast food is high in sodium, saturated fat, trans-fat, and cholesterol, thus damaging the cardiovascular system. Frequent use of fast and fried food can cause high blood pressure, heart disease, dyslipidemia and obesity. Researchers have documented that hypertension and hyperlipidemia during adulthood enhance the risk of coronary artery disease later in life (21). Physical inactivity worsens the situation. The WHO recommends at least 150 minutes of moderateintensity aerobic physical activity per week or 75 minutes of intense brisk physical activity in a week, for adults aged 18-64. Physical activity is inversely related to all-cause mortality and physical inactivity doubles the CVD risk (22). A study performed among Brazilian adolescents identified that moderate to vigorous physical activity and short screen time reduced the CVD risk (23). Physical activity not only reduces premature mortality but also controls CVD risk factors such as hypertension, type 2 diabetes, high cholesterol, and proved to be a simple, cost-effective, practicable, primary prevention strategy to control CVD among youth (24).

The practices and daily activities were found to be optimum as $62 \%$ of the respondents scored more than the mean practice score (34.22). Most of the respondents were physically active and had frequent fruit and vegetable intake. According to the American Heart Association report, consumption of three or more servings of vegetables every day lowers the risk of carotid atherosclerosis by $5 \%$, in adult females (25). However, the majority of the respondents were also involved in the frequent intake of fast food, fried food, and snacks. A balanced and healthy diet is beneficial for health and needs to be promoted to avoid the potential risk of CVD. Stressful life and frequent use of electronic gadgets were also found to be the marked features among the survey population. Stress-related psychosocial ailments are associated with an increased risk of CVD (26). Overall, the practices were optimum among the survey population.

It was identified from the brief medical history of the participants that $69 \%$ of the participants had at least one of the CVD risk factors in terms of family history and/or carrying a risk factor themselves, which is significant. Family history is a strong predictor for the occurrence of CVD in the offspring (27). Various CVD risk traits such as Diabetes, Hypercholesterolemia, Hypertension, and premature CVD mortality are hereditary by nature (28). In the current study, $58 \%$ of respondents had a family history of diabetes, $35 \%$ had a family history of hypercholesterolemia, and $36 \%$ had a family history of CVD which is quite alarming. Familial hypercholesterolemia is strongly associated with the occurrence of CVD (29). A family history of premature death due to myocardial infarction in a blood relative is also significant and indicate probing into genetic problems like dyslipidemia.

Hypertension is a substantial determinant of CVD (30). A survey, that was performed to determine the prevalence of hypertension in middle and low-income countries reported that 1 in 3 adults of developing countries is hypertensive (31). This is an alarming situation as one-third of the Asian population is suffering from a major CVD threat. In the current study, 13 (9\%) respondents were diagnosed as hypertensive, although the survey population belonged to the younger age group 18 to 40 . Among 140 subjects, $17(12 \%)$ were identified as smokers. Cigarette smoking is a leading cause of CVD morbidity and mortality after hypertension (32). Smoking cessation programs and anti-tobacco seminars to spread awareness about the lethal effects of smoking are highly recommended. There is no safe level of smoking exists for the prevention of CVD and stroke. Smoking one to two cigarettes in a day is associated with the same risk as smoking a pack of 20 cigarettes (33). Therefore, smokers should aim to refrain from smoking instead of cutting down or switching to other alternatives, to lessen their risk of 
developing CVD. Vaping which is smoking an ecigarette and recommended as a conventional cigarette alternative is equally harmful and should be discouraged (34). In the current study, a medical history of diabetes was reported in $9(6.4 \%)$ respondents. Various studies worldwide showed that Diabetes has a contribution to the mortality and morbidity rate due to heart attack and stroke and increases the likelihood of developing CVD at an earlier age (35).

Eight $(6 \%)$ of the respondents were using medication for the control of high blood cholesterol. Hypercholesterolemia is strongly related to obesity and hypertension (36). Obesity increases the risk of heart failure and weight management is critical in reducing the potential risk of heart failure (37). Atherosclerotic cardiovascular disease (ASCVD) due to cholesterol deposition on vascular walls is significantly pervasive in South Asians (38). This is a substantial indicator of increased CVD mortality and morbidity in this region. Various factors play a role in the high prevalence of ASCVD among the South Asian population, such as consumption of fatty diet, less intake of fruits and vegetables, sedentary lifestyle, and socioeconomic stress (39). These findings suggest the need for mass screening for these substantial risk factors among the communities.

\section{Conclusion}

The current study has highlighted the awareness level, attitude, and practices regarding CVD risk factors and their prevalence among college students, in an urban setting. It has been established that the level of knowledge about CVD and its risk factors is adequate among the younger population. A positive attitude is seen among the majority of the participants for the avoidance of CVD risk factors. However, lifestyle practices and dietary habits need to be cautioned and improved. The study also highlighted that CVD risk factors are highly pervasive among young adults. Hence, health awareness campaigns among the population, mass screening programs, and lifestyle modifications need to be addressed for the primary prevention of CVD from an early age.

\section{Further Research}

While this research was conducted to the best of our abilities considering the time constraints, some other factors have to be taken into consideration. The majority of the Pakistani people, around $60 \%$, resides in rural areas. Since the urban population was evaluated, we must consider that the urban population have a better literacy rate and access to healthcare. Furthermore, we must also consider the unhealthy lifestyle practices and the involvement of the youth in the consumption of junk food and addictive substances. Pollution and socio-economic factors such as stress also play a part in the final results. Rural areas have lower levels of pollution and a healthier, more active lifestyle. Their lack of resources, awareness, education, and negligible healthcare facilities must also be addressed. Further research can be conducted through a large-scale survey to compare the beliefs, values, and awareness between the urban and rural population.

Ethics approval: This research was approved by the Ethics Committee of the United Medical and Dental College, Karachi. All students were provided written informed consent before enrolment into the study.

\section{References}

1. Yusuf S, Joseph P, Rangarajan S, Islam S, Mente A, Hystad $\mathrm{P}$, et al. Modifiable risk factors, cardiovascular disease, and mortality in 155722 individuals from 21 high-income, middle-income, and low-income countries (PURE): a prospective cohort study. Lancet. 2020;395(10226):795-808.

2. Legido-Quigley $H$, Naheed A, de Silva HA, Jehan I, Haldane V, Cobb B, et al. Patients' experiences on accessing health care services for management of hypertension in rural Bangladesh, Pakistan and Sri Lanka: A qualitative study. Atinga RA, editor. PLoS One [Internet]. 2019 Jan 25 [cited 2020 Aug 16];14(1):e0211100. Available from: https://dx.plos.org/10.1371/journal.pone.0211100

3. Zubair F, Nawaz SK, Nawaz A, Nangyal H, Amjad N, Khan MS. Prevalence of cardiovascular diseases in Punjab, Pakistan: a cross-sectional study. J Public Heal. 2018 Oct 1;26(5):523-9.

4. Ejaz S, Afzal M, Hussain M, Sarwar H, Gilani SA. Knowledge, Attitude and Practice Regarding Modifiable Risk Factors of Cardiovascular Diseases Among Adults in Rural Community, Lahore. Int J Soc Sci Manag [Internet]. 2018 Jul 27 [cited 2019 Mar 14];5(3):76-82. Available from: https://www.nepjol.info/index.php/IJSSM/article/vie $\mathrm{w} / 19902$

5. Feisul Idzwan Mustapha MPH, Shiehafiel Fieqri Hussin MD, Rosnah Ramly MPH. KOSPEN: From the community, for the community, by the community. ASM Sci J. 2020;13(Specialissue5):20-3.

6. Tzoulaki I, Elliott P, Kontis V, Ezzati M. Worldwide Exposures to Cardiovascular Risk Factors and Associated Health Effects: Current Knowledge and Data Gaps. Circulation. 2016;133(23):2314-33. 
7. Liaquat A, Javed Q. Current Trends of Cardiovascular Risk Determinants in Pakistan. Cureus [Internet]. 2018 Oct 4 [cited 2020 Jul 10];10(10):e3409. Available from: /pmc/articles/PMC6284873/?report=abstract

8. Andersson C, Vasan RS. Epidemiology of cardiovascular disease in young individuals. Nat Rev Cardiol. 2018 Apr 1;15(4):230-40.

9. Birck MG, Goulart AC, Lotufo PA, Benseñor IM. Secondary prevention of coronary heart disease: A cross-sectional analysis on the Brazilian longitudinal study of adult health (ELSA-Brasil). Sao Paulo Med J. 2019;137(3):223-33.

10. Carbone S, Canada JM, Billingsley HE, Siddiqui MS, Elagizi A, Lavie CJ. Obesity paradox in cardiovascular disease: Where do we stand? Vasc Health Risk Manag. 2019;15:89-100.

11. Ali Khan Khuwaja, Saima Lalani, Iqbal Syed Azam, Badar Sabir Ali, Abdual Jabbar and RD. Cardiovascular Disease-Related Lifestyle Factors among People with Type 2 Diabetes in Pakistan: AMulticentre Study for the Prevalence, Clustering, and Associated Sociodemographic Determinants Ali. Cardiol Res Pract. 2011;1-8.

12. Wekesah FM, Kyobutungi C, Grobbee DE, KlipsteinGrobusch K, Murunga F, Wekesah W; Understanding of and perceptions towards cardiovascular diseases and their risk factors: a qualitative study among residents of urban informal settings in Nairobi. BMJ Open [Internet]. 2019 [cited 2020 May 10];9:1-9. Available from: http://bmjopen.bmj.com/

13. Barolia RAHS. Risk factors of cardiovascular disease and its recommendations in Pakistani context. J Pakistan Med Assoc [Internet]. 2017 [cited 2020 May 24];67(11):1723-9. Available from: https://jpma.org.pk/article-details/8442

14. Mohammad NB, Rahman NAA, Haque M. Knowledge, Attitude, and Practice Regarding the Risk of Cardiovascular Diseases in Patients Attending Outpatient Clinic in Kuantan, Malaysia. J Pharm Bioallied Sci [Internet]. 2018 [cited 2019 Jun 10];10(1):7$14 . \quad$ Available from: https://www.ncbi.nlm.nih.gov/pmc/articles/PMC588 $7653 /$

15. Marium Mustaqeem, Samiyah Sadullah, Muhammad Zain Farooq, Wajiha Waqar T, Raza Fraz. KNOWLEDGE AWARENESS AND BEHAVIOUR OF NON-MEDICAL STUDENTS ABOUT CARDIOVASCULAR DISEASES. J Ayub Med Coll Abbottabad [Internet]. 2015 [cited 2019 Oct 4];27(4):894$9 . \quad$ Available from: https://pdfs.semanticscholar.org/ec67/18c83ffc39633d 0242d5d8f231ce4c4fdd7b.pdf?_ga=2.79767504.618058196 .1570163115-603759389.1566809348

16. Waśniowska A, Kopeć G, Szafraniec K, Kozela M, Sarnecka A, Knap K, et al. Knowledge of cardiovascular disease (CVD) risk factors in population of Małopolska voivodeship in two independent cross-sectional studies. Przegl Epidemiol. 2018 Jan 1;72(1):75-85.

17. Boateng D, Wekesah F, Browne JL, Agyemang C, AgyeiBaffour P, De-Graft Aikins A, et al. Knowledge and awareness of and perception towards cardiovascular disease risk in sub-Saharan Africa: A systematic review. PLoS One. 2017;12(12).

18. Bairey Merz CN, Andersen H, Sprague E, Burns A, Keida M, Walsh MN, et al. Knowledge, Attitudes, and Beliefs Regarding Cardiovascular Disease in Women: The Women's Heart Alliance. J Am Coll Cardiol. 2017 Jul 11;70(2):123-32.

19. Amini F, Mohini C, Seghayat M. Public health concerns: Knowledge and awareness of modifiable CVD risk factors in Kuala Lumpur. Eur J Public Health [Internet]. 2018 Nov 1 [cited 2019 Mar 21];28(suppl_4). Available from:

https://academic.oup.com/eurpub/article/doi/10.109 3/eurpub/cky218.257/5192470

20. Binti Abdul Shomad M, Azlina Rahman NA, Iza Rahman NA, Haque $M$. The Prevalence of Cardiovascular Disease Risk Factors among Students of International Islamic University Malaysia, Kuantan Campus ARTICLE INFO ABSTRACT. J Appl Pharm Sci [Internet]. 2016 [cited 2019 Mar 18];6(03):51-057. Available from: http://www.japsonline.com

21. Tran DMT, Zimmerman LM, Kupzyk KA, Shurmur SW, Pullen $\mathrm{CH}$, Yates BC. Cardiovascular risk factors among college students: Knowledge, perception, and risk assessment. J Am Coll Heal. 2017;65(3).

22. Zachariah, Alex AG. Exercise for prevention of cardiovascular disease: Evidence-based recommendations. J Clin Prev Cardiol [Internet]. 2017 [cited 2019 Mar 28];6(3):109. Available from: http:/ / www.jcpconline.org/article.asp?issn=2250-

3528; year $=2017$; volume $=6$; issue $=3$; spage $=109$; epage $=114$ ;aulast=Zachariah

23. Cureau F V., Ekelund U, Bloch K V., Schaan BD. Does body mass index modify the association between physical activity and screen time with cardiometabolic risk factors in adolescents? Findings from a countrywide survey. Int J Obes [Internet]. 2017 Apr 1 [cited 2020 Jul 24];41(4):551-9. Available from: https:// pubmed.ncbi.nlm.nih.gov/27867201/

24. Lear S, Hu W, Rangarajan S, Gasevic D, Lancet DL-T, 2017 U. The effect of physical activity on mortality and cardiovascular disease in 130000 people from 17 highincome, middle-income, and low-income countries: the PURE. Lancet [Internet]. 2017 [cited 2020 Jul 24];390(101113):Pages 2643-2654. Available from: https://www.sciencedirect.com/science/article/pii/S0 140673617316343

25. Benjamin EJ, Virani SS, Callaway CW, Chamberlain AM, Chang AR, Cheng $S$, et al. Heart disease and stroke statistics - 2018 update: A report from the American Heart Association. Circulation. 2018;137(12). 


\section{Cardiovascular Disease Risk Factors' Awareness and Prevalence among College Students in Karachi City}

26. Song H, Fang F, Arnberg FK, Mataix-Cols D, De La Cruz LF, Almqvist C, et al. Stress related disorders and risk of cardiovascular disease: Population based, sibling controlled cohort study. BMJ. 2019;365:1-10.

27. Bittencourt MS. Family History of Cardiovascular Disease: How Detailed Should It Be? Mayo Clin Proc [Internet]. 2018 Sep 1 [cited 2019 Mar 21];93(9):1167-8. Available http://www.ncbi.nlm.nih.gov/pubmed/30093169

28. Shakeel M, Irfan M, Khan IA. Estimating the mutational load for cardiovascular diseases in Pakistani population. Chaubey G, editor. PLoS One [Internet]. 2018 Feb 8 [cited 2020 May 24];13(2):e0192446. Available from: https://dx.plos.org/10.1371/journal.pone.0192446

29. Faggiano P, Pirillo A, Griffo R, Ambrosetti M, Pedretti $R$, Scorcu G, et al. Prevalence and management of familial hypercholesterolemia in patients with coronary artery disease: The heredity survey. Int J Cardiol [Internet]. 2018 Feb 1 [cited 2019 Mar 23];252:193-8. Available from: http://www.ncbi.nlm.nih.gov/pubmed/29249427

30. Coutinho BL da S, Brito RA, Conceição AIC de C, Cardoso F de J, Santos AS dos, Lopes BFF, et al. Hypertension Associated with Atherosclerosis Risk Factors in Patients of Family Health Strategy Highlighting the Framingham Risk Score. Open J Prev Med [Internet]. 2018 Aug 3 [cited 2019 Mar 23];08(08):229-47. Available from: http://www.scirp.org/journal/doi.aspx?DOI=10.4236/ ojpm. 2018.88020

31. Sarki AM, Nduka CU, Stranges S, Kandala N-B, Uthman OA. Prevalence of Hypertension in Low- and Middle-Income Countries. Medicine (Baltimore) [Internet]. 2015 Dec [cited 2019 Mar 27];94(50):e1959. Available from: http://content.wkhealth.com/linkback/openurl?sid=W KPTLP:landingpage\&an=00005792-201512150-00005

32. Banks E, Joshy G, Korda RJ, Stavreski B, Soga K, Egger $S$, et al. Tobacco smoking and risk of 36 cardiovascular disease subtypes: Fatal and non-fatal outcomes in a large prospective Australian study. BMC Med. 2019;17(1).
33. Hackshaw A, Morris JK, Boniface S, Tang JL, Milenkovi D. Low cigarette consumption and risk of coronary heart disease and stroke: Meta-analysis of 141 cohort studies in 55 study reports. Vol. 360, BMJ (Online). 2018.

34. Alzahrani T, Pena I, Temesgen N, Glantz SA. Association Between Electronic Cigarette Use and Myocardial Infarction. Am J Prev Med. 2018 Oct 1;55(4):455-61.

35. Piepoli MF, Hoes AW, Agewall S, Albus C, Brotons C, Catapano AL, et al. 2016 European Guidelines on cardiovascular disease prevention in clinical practice. Eur Heart J [Internet]. 2016 Aug 1 [cited 2019 Mar 16];37(29):2315-81. Available from: https:/ / academic.oup.com/eurheartj/articlelookup/doi/10.1093/eurheartj/ehw106

36. Turer CB, Brady TM, De Ferranti SD. Obesity, Hypertension, and Dyslipidemia in Childhood Are Key Modifiable Antecedents of Adult Cardiovascular Disease Circulation. Circulation [Internet]. 2018 [cited 2019 Mar 28];137:1256-9. Available from: http:/ / circ.ahajournals.org

37. Ndumele CE, Matsushita $K$, Lazo $M$, Bello $N$, Blumenthal RS, Gerstenblith G, et al. Obesity and Subtypes of Incident Cardiovascular Disease. J Am Heart Assoc. 2016;5(8).

38. Gupta M, Khandelwal A, Krishnan A V, Lichtman JH, Mehta LS, Patel HN, et al. On behalf of the American Heart Association Council on Epidemiology and Prevention; Cardiovascular Disease and Stroke in Women and Special Populations Committee of the Council on Clinical Cardiology; Council on Cardiovascular and Stroke Nursing; Council. Circulation [Internet]. 2018 [cited 2019 Mar 28];138:1-34. Available from: http:/ / ahajournals.org

39. Anoop S, Abhishek V, Vaidya R, Misra A, Mohan V, Soares MJ, et al. Body fat, metabolic syndrome and hyperglycemia in South Asians. J Diabetes Complications [Internet]. 2018;32(11):1068-75. Available from: https://doi.org/10.1016/j.jdiacomp.2018.08.001 